\title{
Formação de professores na prática política do MST: a construção da consciência orgulhosa
}

Sonia Aparecida Branco Beltrame

Universidade Federal de Santa Catarina - UFSC

\section{Resumo}

Este artigo propõe-se a discutir a experiência de professores e professoras das escolas de assentamento organizadas pelo Movimento dos Trabalhadores Rurais Sem-Terra - MST, no oeste catarinense. Seguindo uma metodologia qualitativa, o estudo possibilitou a apreensão de aspectos significativos do universo cultural dos sujeitos, destacando as relações construídas na vida familiar, no desempenho da profissão e na participação política no Movimento.

A análise da ação desenvolvida pelos professores nos diversos espaços de atuação vai revelando como eles se tornam sujeitos de sua experiência. A adesão às propostas educativas do MST possibilita a manifestação de uma identidade que fortalece a experiência cotidiana de ser professor, favorecendo o desenvolvimento de uma consciência orgulhosa da prática docente. A experiência é realimentada na escola e também nas instâncias educativas propiciadas pelo Movimento, nos contatos com o grupo de docentes, nos estudos que desenvolvem, nas trocas com os alunos e seus familiares. 1sso possibilita aos professores estabelecer prioridades, acrescentando elementos significativos aos conteúdos escolares. Evidencia-se aí a perspectiva de veiculação, na escola, de uma dimensão do saber enriquecido pela ação política gerada nas práticas coletivas. Esse envolvimento resulta em experiências diferenciadas que se refletem nas ações desenvolvidas na escola e no Movimento. Com isso, esses professores reelaboram o espaço da escola no meio rural, criando novos compromissos que transformam sua atividade docente, ampliando seu aprendizado e as relações de solidariedade presentes na cultura do campo.

\section{Palavras-chave}

Escola - Professores - Movimentos sociais - Consciência orgulhosa.

Correspondência:

Sonia Beltrame

Caixa Postal 491

88010-970 - Florianópolis - SC

e-mail: sonia@ced.ufsc.br 


\section{Teacher education in the political practice of the MST: the construction of the proud consciousness}

Sonia Aparecida Branco Beltrame

Federal University of Santa Catarina

\section{Abstract}

This article proposes a discussion about teachers' experience at settlement schools organized by the MST - Brazilian Landless Workers Movement in western Santa Catarina. Following a qualitative methodology the study allowed the understanding of significant aspects of the cultural universe of the agents involved, highlighting the relationships built in family life, in the exercise of the profession, and in the political participation in the Movement.

The analysis of the actions carried out by the teachers in various spheres reveals how they become agents of their own experience. Joining the education proposals of the MST allows in these teachers the manifestation of an identity that strengthens the everyday experience of being a teacher, promoting the development of a proud consciousness of the teaching practice. The experience is fed back to the school and to other educational opportunities promoted by the MST, to the contact with the group of teachers, to the studies they carry out, and to the exchanges with students and their families. That allows teachers to set priorities, adding significant elements to the contents seen at school.

The prospect is then revealed for the transmission at school of a dimension of knowledge enhanced by the political action engendered in collective practices. This involvement results in differentiated experiences with benefit to the actions developed at school and in the Movement. Thus, these teachers re-establish the role of the school in the rural areas, creating new commitments that transform their teaching activity, broadening their learning and the relationships of solidarity present in the countryside culture.

\section{Keywords}

School - Teachers - Social movements - Proud consciousness. 
Neste trabalho pretendo discutir o fazer docente, cujo sujeito, o professor, ' acumula saberes que vão além dos conhecimentos formais. Esses saberes que ele traz da vida rural, re-significados na luta social, constituem o ingrediente fundamental de produção do conhecimento escolar. Para a análise da construção desses saberes é fundamental a contribuição de estudiosos do tema da formação de professores, como Nóvoa, Tardif e Perrenoud, inspiradores do presente estudo.

Não tenho a intenção de analisar o MST na totalidade de seus aspectos históricos, políticos e ideológicos, considerando sua extensão e complexidade para os limites deste trabalho. Situo apenas uma expressão local, focalizando aspectos reveladores das questões mais universais dos movimentos sociais. Nesse sentido, recorro a Melucci (1997) para dizer que um movimento social é composto de naturezas diversas, por isso precisamos decompor sua aparente homogeneidade. Em nome dessa complexidade, restrinjo minha análise a uma expressão desse Movimento no oeste catarinense e aos professores das escolas de assentamento ali situadas. Recorro, então, mais uma vez a Melucci para enfatizar que "o que nós chamamos de movimento social, muitas vezes, contém uma pluralidade de elementos e devemos ser capazes de distingui-los se quisermos entender o resultado de uma ação coletiva" (Melucci, 1989, p. 57). Por isso a importância dos estudos sobre as ações desses sujeitos em seus diferentes enfoques e abordagens, possibilitando analisar as suas formas de organização e suas maneiras de enfrentamento das situações de tensão.

Essas reflexões são fundamentais para compreender a ação de uma organização como o Movimento dos Trabalhadores Rurais SemTerra, que se apresenta como

um movimento sociocultural cujo centro motriz está no processo de formação do sujeito Sem-Terra, que também se produz como um sujeito cultural, à medida que suas ações e sua forma de atuação na sociedade produzem e reproduzem um determinado modo de vida que ao mesmo tempo recupera, consolida e projeta valores, princípios, convicções e também um determinado jeito de conceber as relações sociais. (Caldart, 1999, p.178)

O MST se propõe a juntar suas ações às práticas da instituição escolar na zona rural, apostando na formação dos professores e buscando uma qualidade política para a escola, cuja história está marcada pelas precariedades e pelo controle exercido por inúmeros projetos e políticas públicas para as áreas rurais.

Esse é o eixo central do presente estudo. 0 trabalho que desenvolvo busca responder a questões como: a construção do saber docente ligado a um movimento social no campo qualifica o professor para uma trajetória diferente? Aponta uma nova maneira de ensinar na escola do meio rural? Como é construído esse fazer, que saberes são mobilizados?

As respostas a essas questões, que vão sendo construídas ao longo do estudo, evidenciam que a formação docente não se limita aos espaços explicitamente designados para tal. A formação é constantemente consolidada ou enfraquecida pelos estímulos que o professor recebe no dia-a-dia (Perrenoud, 1997, p. 87).

0 universo dos professores, homens e mulheres, apresenta um repertório rico em experiências que marcam suas trajetórias e desvendam a forma como organizam seu cotidiano a partir das referências culturais do mundo rural e do envolvimento político.

0 material empírico colhido possibilita reconstruir aspectos do universo cultural desses sujeitos, destacando as relações construídas na vida familiar, no desempenho da profissão e na participação política no MST. A experiência educativa desenvolvida nas escolas de assenta-

1. Optei por utilizar o masculino genérico sempre que este expressar 0 conjunto da categoria docente e destacar a diferenciação entre professores e professoras sempre que esta se fizer necessária. 
mento vem enriquecida por essas vivências, possibilitando trocas significativas com os alunos, evidenciando características da cultura rural que supõem o convívio e a solidariedade.

A experiência pedagógica se alimenta na prática política, num processo coletivo de busca de melhoria da vida no campo. As relações que o Movimento constrói com os docentes proporciona a estes um sentimento positivo em relação a seu fazer, resgatando seu papel social. Nas relações com o mundo rural os professores desenvolvem uma prática que se dá em várias dimensões: produtiva, política e educativa. "São espaços nos quais, como sujeito criador, está envolvido em atividades práticas, elaborando um saber socialmente relevante" (Therrien, 1993, p. 46).

Em seu dia-a-dia, esses homens e mulheres, no trabalho, no contato direto com a natureza, participam intensamente dos ciclos da vida e, nessa dinâmica, vão elaborando conhecimentos e relações que os enriquecem como professores.

Considerando todos esses aprendizados, o saber docente aparece "como um saber plural, formado por um amálgama, mais ou menos coerente, de saberes oriundos da formação profissional, dos saberes das disciplinas, dos currículos e da experiência” (Tardif, 1991, p. 86).

A proposta do MST de investir no processo de formação de sujeitos, dentro do espaço oficial de ensino, ou seja, da escola pública, é um desafio, uma vez que não são freqüentes experiências desse tipo. Por isso, a análise desse trabalho no contexto da escola rural, no sul do país, se apresenta repleta de complexidades, desafios e possibilidades.

Além disso, são raros os estudos da prática docente que relacionam as dificuldades da profissão com os desafios que os professores vivem como homens e mulheres no seu cotidiano. Considero importante investigar como eles enfrentam as dificuldades profissionais e garantem, ao mesmo tempo, o espaço para sonhos, necessidades, esperanças e projetos de vida.
Como destaca Nóvoa, ser professor “obriga a opções constantes, que cruzam a nossa maneira de ser com a nossa maneira de ensinar, e que desvendam, na nossa maneira de ensinar, a nossa maneira de ser" (1995, p. 2). Tal percepção é partilhada com outros autores, que enfatizam a importância dos estudos que contemplam a compreensão da vida do professor (Goodson, 1992; Perrenoud, 1997; Kramer; Souza, 1994; Cavaco, 1995; Moita, 1995; Sacristan, 1995).

No percurso metodológico que desenvolvo, três vetores conduzem a análise dos dados colhidos: a) como os professores se constroem enquanto homens e mulheres que vivem na zona rural; b) sua atuação em escolas de assentamento; c) a participação num movimento social que reivindica a cidadania para as populações que vivem no campo. Para melhor encaminhamento do estudo, foi necessário às vezes analisar cada aspecto isoladamente. No entanto, tenho clareza de que na prática dos sujeitos, essas dimensões não se desvinculam.

As análises das práticas dos atores investigados apontaram para a possibilidade da melhoria da qualidade do trabalho do professor das escolas de assentamento. 0 envolvimento desses docentes nas propostas do MST redimensiona sua ação na escola, tornando-os mais seguros para fazer escolhas e acrescentar elementos significativos aos conteúdos escolares organizados pelos sistemas de ensino aos quais estão vinculados. Com isso esses professores reelaboram o espaço da escola no meio rural.

\section{Os caminhos da pesquisa}

Para o desenvolvimento da pesquisa, optei por uma abordagem metodológica qualitativa, referendada nos estudos de Calvo (1992), Rockwell (1987), André (1995) e Mercado (1994), que me permitiu, a partir do ir e vir constante entre observações e reflexão teórica, reordenar e reconceitualizar o objeto de 
estudo, tornando visíveis relações e significados antes opacos.

Nessa perspectiva, valorizo um percurso teórico metodológico construído à medida que o pesquisador toma conhecimento do universo do "outro", interagindo com ele de maneira a não "abafar" sua voz, ou seja, documentando e interpretando conforme sua perspectiva teórica; sua voz é o núcleo que articula as vozes dos outros, que também devem ser suficientemente reconhecíveis e não permanecer totalmente dependentes da voz do pesquisador (Mercado, 1994).

Esse percurso metodológico possibilitou a investigação da prática docente nos seus diversos desdobramentos, para além do espaço da sala de aula, apreendendo as redes de relações construídas pelos docentes nos seus diversos pertencimentos.

A coleta de dados desenvolveu-se num universo de 14 professores, doze mulheres e dois homens que atuam nas escolas de assentamento no município de Abelardo Luz, situado na região oeste de Santa Catarina, distante cerca de $615 \mathrm{~km}$ de Florianópolis. A escolha dos sujeitos investigados foi facilitada pelo envolvimento que esta pesquisadora já possuía com os docentes por trabalhos anteriormente realizados na região. Procurei formar um grupo de professores que apresentassem características tais como: experiência em classe multisseriada; juventude e pouca experiência; mãe e filha professoras; formação superior; posição de liderança no Movimento; marido e mulher na profissão; professores homens; não habilitação para a docência. Todos os professores pesquisados fazem parte do quadro administrativo municipal, não existindo, portanto, nenhuma espécie de vínculo empregatício com o MST.

Dentro dos procedimentos metodológicos adotados para o desenvolvimento da pesquisa, procurei reunir as informações de forma abrangente, incluindo levantamento das publicações do Movimento, entrevistas com os professores, comparecimento aos eventos orga- nizados pelo Movimento; visitas e observações nas escolas.

A observação da prática dos professores constituiu uma etapa da pesquisa permeada por desafios e dificuldades. Minha vivência com a sala de aula no ensino das séries iniciais, em que também fui professora no início da carreira docente, não me ajudou a superar a desconfortável tarefa de fazer observações em sala de aula. Inicialmente, senti-me invasora ao sentar na classe de um professor e fazer anotações. Quando consegui superar esse constrangimento, deparei-me com um certo desencontro entre o que eu queria realmente conhecer e o que me era dado observar. Essa sensação impedia que a sala de aula se mostrasse para mim em toda a sua riqueza. Buscando entender o que se passava com meu "olhar observador", encontrei na literatura pedagógica referências que contribuíram para ampliar minha visão da escola e do trabalho docente.

Nóvoa (1995, p. 16) afirma que as escolas constituem uma territorialidade espacial e cultural onde se exprime o jogo dos atores educativos internos e externos e que, portanto, a análise de sua prática só tem sentido se conseguir mobilizar todas as dimensões pessoais, simbólicas e políticas da vida escolar, não reduzindo o pensamento e a ação educativa a perspectivas técnicas, de gestão ou de eficácia stricto sensu. Por isso, nas análises da prática docente é necessário contemplar esse conjunto de elementos que compõem o fazer pedagógico na sua amplitude.

Essa perspectiva veio ao encontro dos propósitos que estavam amadurecendo nos meus questionamentos sobre os rumos da pesquisa. Ou seja, a possibilidade de observar a ação dos docentes se alargou na medida em que se ampliou meu conceito de formação docente. Abriu-se então um enorme leque de possibilidades de observação da ação docente. Passei a acompanhar os professores em diversas situações: cotidiano da vida camponesa; eventos políticos e pedagógicos do Movimento; reuniões pedagógicas dos pequenos grupos; 
encontros de mulheres agricultoras; congressos das crianças sem-terra; sala de aula. Diante de tal diversidade de situações que mereciam acompanhamento - e a abrangência do universo investigado -, estabeleci algumas prioridades, o que impediu uma observação profunda em sala de aula, mesmo reconhecendo a importância desse espaço para a compreensão do trabalho docente. Fiz algumas visitas às escolas e recortei o que estou denominando "cenas da sala de aula”, em que registrei momentos da vida escolar que enriquecem os demais elementos da análise.

Longe de pretender uma análise do desempenho dos professores em sala de aula, destaquei momentos que esclarecem e completam suas falas e ao mesmo tempo revelam situações que ajudam a refletir sobre a docência na zona rural. Observei situações típicas desse universo nas relações dos alunos entre si e com o professor que ampliam a compreensão da prática ali desenvolvida. Escolhi salas de aula de professores entrevistados em etapas anteriores dessa pesquisa e que se mostraram receptivos à minha presença.

0 material produzido pelo MST ao longo dos últimos dez anos também foi objeto de minha análise. Nesses documentos estão registrados os princípios norteadores de suas ações, bem como seu percurso histórico. Dediquei maior atenção aos que explicitam sua proposta de educação, por ser o aspecto que privilegiei nas análises em relação ao MST.

Também preparei um registro das observações feitas em todas as visitas, um diário de campo, detalhando situações e acontecimentos que contribuiram para apreender o universo investigado. Esse material complementa ou esclarece informações dadas pelos atores pesquisados.

Organizei as entrevistas de maneira aberta, possibilitando aos professores construir seu percurso de vida da infância à vida adulta, com dados de origem familiar, formação escolar e profissional, cidades onde viveram, acontecimentos marcantes na infância e na adoles- cência e, finalmente, o envolvimento com o MST.

Nas visitas familiares, era possível notar uma preparação cuidadosa da casa e da refeição servida, o que demonstrava a hospitalidade característica desse meio, bem como o interesse que dispensavam pelo meu trabalho. Destaco essa receptividade e a disponibilidade das professoras entrevistadas confrontando com comportamentos comuns entre grupos de docentes investigados na zona urbana. Carvalho, refletindo sobre os procedimentos metodológicos utilizados em pesquisa com professores na periferia de São Paulo, afirma:

Para mim, um aspecto surpreendente foram as restrições a que a entrevista fosse feita em suas casas, fora do horário de trabalho. Todos eles colocaram dificuldades nessa direção e preferiram marcar entrevistas durante o Horário de Trabalho Pedagógico, isto é, nos horários em que deveriam permanecer na escola para participar de reuniões com seus colegas.

A autora nos conta que uma professora propôs que a entrevista ocorresse durante as aulas, enquanto as crianças faziam exercícios, e assim foi feito. Analisando as razões que levavam a essas atitudes restritivas, a autora levanta duas ordens de explicações: em primeiro lugar, o fato de considerarem a participação na pesquisa como parte de seu trabalho na escola; em segundo lugar, essa restrição parecia expressar uma concepção de privacidade característica de certos grupos das camadas médias urbanas, que consideram o lar e a família como espaços invioláveis, a serem preservados de estranhos (Carvalho, 1999, p 117). Na reflexão acima é possivel compreender a forma como as populações camponesas organizam as suas relações pautando-se pela cordialidade e afeto, diferentemente da maneira como isso ocorre na cidade. Isso evidencia a natureza diversa de situações e contextos com os quais se depara o pesquisador, o que requer distintos encaminhamentos metodológicos. 


\section{Os momentos de formação do sujeito professor}

A formação dos docentes que atuam nas escolas de assentamento se beneficia de um conjunto de práticas formativas oferecidas pelo Movimento. São eventos que ora provocam grande mobilização, ora atraem pouca adesão por parte dos docentes. Mas todos representam espaços fundamentais tanto para a formação docente e política desses sujeitos, quanto para aquisição do conhecimento a ser socializado na sala de aula.

Ao longo do estudo analiso esses eventos vividos pelos docentes, alguns em espaços institucionais, outros (a maioria) organizados pelo Movimento. Investigo também momentos do cotidiano pedagógico dos professores entrevistados, destacando em cada relato as peculiaridades do ensino nas escolas de assentamento, buscando compreender os vários determinantes que direcionam sua ação.

\section{Os (des)caminhos da formação tradicional}

A discussão sobre a formação docente é por si só complexa, sendo objeto de muitos estudos, nem sempre levados a sério pelos sistemas de ensino, responsáveis pela oferta de oportunidade de estudos contínuos aos professores.

Estudos de Perrenoud (1997, p.95) destacam o controle exercido pelos sistemas escolares sobre a formação dos professores. Esses sistemas só reconhecem um tipo de formação, aquela que é dada pela sua própria escola normal. Dessa maneira são os interesses do sistema que prevalecem na formação dos docentes e dificilmente são consideradas as necessidades de seus alunos. Enfatiza o autor que “a formação de professores só tem hipóteses de se tornar uma força de mudança da escola se adquirir maior autonomia em relação ao sistema" (Perrenoud, 1997, p. 97).

Donde se conclui que uma formação com relativa autonomia poderia trazer inovação nas relações pedagógicas, principalmente se seus sujeitos interagissem com práticas e experiências de outros setores sociais; se houvesse um questionamento das relações de autoridade, atitude comum nas normas dos sistemas; uma diversificação de modelos e práticas sacralizadas e inquestionáveis; e, até, uma abertura a correntes de pensamento ainda marginais na educação (Perrenoud, 1997, p. 97).

As reflexões do autor contribuem para a análise do papel desempenhado pelo MST na relação com os professores das escolas de assentamento. É importante notar que seu envolvimento com a educação formal se encaminha em três direções: a luta pela construção de escolas para os trabalhadores; a orientação pedagógica aos professores que atuam nas escolas, localizadas em áreas de acampamentos e assentamentos rurais; a elaboração de um projeto educativo para o campo. Essa perspectiva difere de outras iniciativas de movimentos sociais que, nos anos 1980, lutaram por escolas nas periferias urbanas e cujas reivindicações não comportavam necessariamente a direção pedagógica dessas instituições. Nas propostas do Movimento para a formação de professores, as necessidades das populações que vivem no campo passam a ser atendidas, pois, além do programa de conteúdos formais, os docentes são orientados a considerar os valores e as tradições culturais em que se socializaram como membros da localidade. Essa é a riqueza da proposta, pois incorpora os saberes locais e abre espaço na escola para a cultura desses homens e mulheres. Dessa maneira, a formação dos professores está levando em conta as condições efetivas da realidade (Perrenoud, 1997, p. 100). Seguindo a linha de reflexão do autor, é fundamental considerar as condições nas quais se realizam as práticas docentes, para evitar que o professor conclua, após alguns anos de atividade, que sua formação não serviu para nada e “(...) dez anos mais tarde, quando lhes propusermos uma formação contínua, dirá que perdeu o interesse por contos de fadas (...)" (Perrenoud, 1997, p. 100).

Essa visão aponta para o conceito de 
que a formação do docente não deve ficar restrita ao período de duração do curso. Ele vai sendo formado ao longo de sua experiência de envolvimento com os alunos, com os pais dos alunos, com os colegas da escola, nas situações de participação política, enfim, no cotidiano. Segundo Perrenoud, essa formação pode ser constantemente consolidada ou, pelo contrário, enfraquecida pela conjuntura que o professor vivencia no dia-a-dia. Nas experiências vividas por docentes de qualquer nível de ensino ocorrem situações que causam satisfação e aprendizagem, elevando a auto-estima; ou, ao contrário, as circunstâncias provocam desânimo e frustração profissional.

A formação é sempre uma "mensagem”, e uma política de formação, para ser conseqüente, deve ter em conta o conjunto das "mensagens" que os professores recebem (Perrenoud, 1997, p. 103). Para tanto, eles precisam estar constantemente recebendo informações que favoreçam a recepção dessas “mensagens" do cotidiano. Esse repertório cultural apresenta grande riqueza, construída na permanente relação de aprendizagem entre crianças e adultos, na observação atenta dos fenômenos naturais a que estão sujeitos e na prática da solidariedade.

As escolas deveriam levar em conta a possibilidade de subsidiar os professores com as informações necessárias para uma formação constante. Assim, as relações costumeiramente autoritárias e burocratizadas entre docentes e administradores do sistema de ensino poderiam se transformar no que Perrenoud chama de "animação pedagógica", entendida na sua essência como a ajuda prestada ao professor para que ele possa conciliar a formação inicial ou contínua com as condições locais da prática. 1sso, infelizmente, não é feito nas escolas urbanas nem nas dos assentamentos - embora seja o que se propõe o Movimento nas ações formativas que têm por objeto os professores envolvidos com sua proposta pedagógica.

\section{A formação na proposta do MST}

Na trajetória dos professores investigados, a formação docente tradicional teve pequeno peso, ou seja, poucos professores tiveram formação regular para a profissão. Observando o requisito idade/série, constatei que, dos 14 docentes investigados, apenas uma professora havia feito o Magistério, na adolescência, momento em que normalmente se cursa o ensino médio. Sua motivação teve razões que não a encaminhavam para a profissão. A escolha, segundo ela, foi ditada pela facilidade e pelo baixo custo financeiro do Magistério: "Fui fazer o curso que mais convinha, fácil e que não exigia que a gente gastasse muito" (Terezinha). ${ }^{2}$

Os demais docentes entrevistados não tiveram formação específica como professores. Alguns passaram a lecionar a partir do envolvimento com o Movimento.

A história dos entraves na formação dos professores segue um conjunto de situações vividas no cotidiano camponês, revelando as peculiaridades desse contexto. A falta de oportunidades para estudar e os percalços enfrentados na escolaridade aparecem nas suas trajetórias profissionais e pessoais. Poucos foram além das quatro primeiras séries, outros iniciaram e não concluíram, como conta Marialva: "Comecei o $2^{0}$ grau, mas desisti, era muito puxado, eu morava e trabalhava numa casa para poder estudar”. E há também os que fizeram cursos não ligados ao Magistério, como Lucy: "Eu fiz o científico, pois queria fazer o vestibular".

É conhecida a precariedade da formação docente nas escolas rurais, sendo objeto de estudos que destacam, entre outros, problemas como: os poucos anos de escolaridade; a falta de propostas de formação contínua por parte dos órgãos gerenciadores dos sistemas de ensino; inadequação da formação supletiva para

2. Todos os nomes dos professores são fictícios. 
professores das zonas rurais (Therrien, 1993; Alencar, 1993; Davis; Gatti, 1993; Fonseca, 1989; Arroyo, 1987; Brandão, 1983).

Em seus depoimentos, os professores evidenciam as carências resultantes da sua formação precária e as dificuldades ainda presentes no seu cotidiano na escola. Afirmam que essa fragilidade os deixa vulneráveis às ingerências e arranjos políticos eleitoreiros locais, principalmente nos momentos de contratação, efetuados pelas instituições municipais e estaduais.

Essa formação precária é sentida por eles como um entrave à prática, sendo lamentada na maioria dos relatos, que revelam ainda as dificuldades enfrentadas nos primeiros anos de atuação profissional e os esforços para superar a situação. A professora Antonieta conta que aprendeu com as amigas, "quando vinham na minha casa, conversavam sobre escola eu escrevia tudo". Já Margarida recorreu aos livros que encontrou na escola: "Fui aprendendo fazendo...". No caso de Adeodato, o aprendizado dependeu de um esforço pessoal penoso: "No começo foi difícil, deu muito serviço. Teve noites que eu ia dormir uma e meia ou duas horas da madrugada, eu tive que espernear".

As soluções encontradas por cada professor para superar os problemas os ajudaram também a aumentar sua segurança em sala de aula. Os docentes recorriam ao que Perrenoud chama de "bricolage", ou seja, a utilização de materiais disponiveis no cotidiano e a referência a situações já experimentadas:

A prática pedagógica na sala de aula não é a concretização de uma teoria, e a sua própria concretização está subordinada ao funcionamento do sistema de esquemas geradores de decisões. (Perrenoud, 1997, p. 40)

Assim, é possível ao professor ir construindo uma competência baseada em seu repertório de experiências culturais somado à aprendizagem que a condição docente lhe possibilita: troca de experiências com colegas, consulta a materiais didáticos disponíveis na escola, convivência com os alunos e seus pais.

Esses saberes, porém, não são suficientes para qualificar o professor, pois não estão fundamentados nos aspectos técnicos da profissão, requisito bastante valorizado pelos sistemas de ensino. Constata-se que professores sem formação institucional, mesmo depois de muitos anos de prática, não se sentem capacitados para a profissão nem legitimados em sua identidade docente, pois acreditam que a formação se dá fundamentalmente num momento, ou seja, no curso realizado na "escola normal". Passam toda uma vida se desculpando por ocupar um lugar que não lhes pertence. Em parte, isso se explica pela maneira como são vistos e tratados pelo sistema de ensino: são remunerados com o menor salário, não têm estabilidade no cargo e suas opiniões e posições são desqualificadas por serem "despreparados” para o exercício profissional. São nomeados nos documentos oficiais como "professores leigos", expressão que carrega um significado negativo entre os docentes - e é contraditória porque designa, como estranhos ao Magistério, profissionais que há anos exercem esse ofício e que deveriam ser reconhecidos em sua identidade profissional, não como "leigos" mas como docentes.

No Movimento, porém, esse professor é visto de outra maneira. Se por um lado ainda é mencionado como "leigo", por outro, as propostas do coletivo destacam valores que vêm de sua prática e o legitimam a ocupar esse espaço com dignidade. Sua valorização profissional se dá tanto na discussão e elaboração conjunta da proposta de educação para as escolas de acampamento e assentamento quanto nas reuniões pedagógicas, quando os relatos das experiências são momentos de reconhecimento da prática educativa, independentemente do nível de escolaridade de cada professor - o que não diminui o estímulo para que os professores tentem ampliar esse nivel nas instituições responsáveis por programas de formação docente. 
$\mathrm{Na}$ verdade, todos gostariam de continuar os estudos, mas seus esforços e iniciativas são muitas vezes frustrados. Embora recebam estímulo do Movimento para superar a defasagem do nível de escolaridade, as saídas encontradas não têm sido suficientes. 0 depoimento de José Maria é representativo do que ouvi com freqüência dos professores:

É, o sonho da gente seria fazer uma faculdade, mas visto pelo que a gente ganha e as dificuldades financeiras que a gente vive hoje, se for uma faculdade particular, a gente não vai conseguir fazer. Se depender de pagar com o que a gente ganha dificilmente algum professor vai conseguir fazer faculdade.

0 que alguns conseguem, e de maneira precária, é realizar cursos de segundo grau supletivo oferecidos na região, como o Projeto Logos. ${ }^{3}$ Docentes com alguma disponibilidade de recursos pagam caro pelos cursos superiores oferecidos pelas instituições fundacionais da região, para atender as exigências da instituição que os contrata.

A investigação evidenciou as condições em que os docentes desenvolvem sua prática pedagógica apresentando as diversas oportunidades de formação profissional e outras possibilidades oferecidas pelo Movimento. Relatei também as vivências do grupo familiar, além de ter demonstrado como os elementos da cultura do campo se integram às atividades de sala de aula.

A análise dessa experiência revela que esses professores exercem um fazer envolto num sentimento positivo, que constrói sua consciência orgulhosa. lsso resulta fundamentalmente de dois componentes: o resgate da vocação docente, num sentido político e relacional; e a vinculação do magistério a um projeto educativo e político amplo. Essa relação qualifica o trabalho como uma vertente importante da luta social que vem sendo construída em torno da causa da terra - e essa perspectiva é um alimento constante da atividade desses professores. Assim, a consciência orgulhosa é um processo que vai se dando no dia-a-dia da profissão.

Os vínculos que unem os professores, como profissionais individualizados, mas principalmente como atores coletivos, revelam o processo dinâmico de construção da identidade que se dá ao longo das experiências desses sujeitos, nos diversos espaços de atuação, na tensão entre permanência e mudança.

A permanência de um sujeito no tempo é garantida pela integração entre passado, presente e futuro, construindo uma biografia individual que the permite diferenciar-se dos demais. A identidade, portanto, se define como o conjunto de representações do eu pelo qual o sujeito comprova que é sempre igual a si mesmo e diferente dos demais (Melucci, 1996; 1997).

No processo de construção da identidade, as experiências são reelaboradas e novos significados se agregam às etapas vividas. Não se trata de um corpo fixo e acabado de representações acerca do eu que cada sujeito atualiza em sua prática, mas de uma elaboração histórica reajustada ao longo das diferentes etapas da vida e de acordo com o contexto onde ele atua, uma construção que exige constantes negociações entre tempos diversos do sujeito e ambientes ou sistemas em que ele se insere (Osores, 1997).

As circunstâncias em que se tornaram professores, as representações que têm de si e do trabalho que desenvolvem revelam os diferentes pertencimentos ao longo das etapas da vida camponesa, profissional e política. Nos diferentes contextos em que atuam como professores e na interação com outros sujeitos, vão estabelecendo trocas fundamentais e agregando conhecimentos reelaborados no cotidiano pedagógico. Suas vivências vão possibilitando o acesso a um

3. Modalidade de ensino criado na década de 70 , com a Lei 5.692/71, para habilitar professores leigos, estimados na época entre 150 a 200 mil no país todo. 
"saber amplo que reúne elementos da formação profissional, das disciplinas, do currículo e da experiência" (Tardif, 1991, p. 87).

Nessas relações os professores dão significado a seu trabalho e aos sentimentos gerados a partir do desempenho docente e os resultados afetivos e profissionais podem causar satisfação ou frustração. Devido aos fortes componentes relacionais e afetivos da profissão, à tensão entre o ideal de dedicação e uma realidade complexa, muitos professores se apóiam na vocação como um recurso disponível. Ou seja, a predisposição para a atividade docente é um elemento importante para garantir o bom desempenho profissional. Essa noção de vocação, que está ligada à idéia de dar "o melhor de si” o faz aceitar com humildade as suas fragilidades. 0 acaso e a intuição, portanto, desempenham um papel importante em grande parte dos êxitos e dos fracassos (Perrenoud, 1997, p. 31).

lsso fica mais explícito entre os professores da zona rural, região onde esse tipo de trabalho conserva uma imagem positiva, não tendo sofrido o desgaste ocorrido nas cidades. 0 desenvolvimento urbano e industrial, a extensão do acesso à escola pública, as políticas educacionais que degradam sistematicamente os salários e a condições de trabalho se refletem nas formas de ação coletiva da categoria, que expõe publicamente sua precária condição de trabalho e os baixos salários (Vianna, 1999, p. 65).

$\mathrm{Na}$ zona rural, destaca-se o papel do professor como articulador das diversas formas da vida associativa local, o que lhe garante prestigio e reconhecimento externo à sala de aula. Esse papel é reforçado pela maneira como se relaciona com os pais dos alunos, que reconhecem a importância social representada pelo professor. Nesse contexto, compreende-se sua recusa em perceber-se a si mesmo como um trabalhador assalariado (Peralva, 1992, p. 51). A recompensa por seu trabalho extrapola os benefícios advindos do salário e dimensiona o fazer docente num espaço de relações e gratificações simbólicas de grande valia.

Peralva destaca ainda que, entre as duas categorias, a do professor que se define pela vocação e a do que apenas se vê como um assalariado, se esconde um tipo intermediário, em que podem ser classificados os professores das escolas de assentamentos: para eles é muito importante gostar da profissão, mesmo que o salário recebido não seja o desejado.

A gente tem amor pelas crianças, nas férias não vê a hora de estar lá com elas. É uma questão de gosto, um dom que a gente tem. Comigo despertou tarde, já com 18 anos, mas valeu a pena. Às vezes, tenho a felicidade de encontrar ex-alunos que vêm me dar parabéns e dizer que foi graças a gente que hoje eles são alguém na vida também. Isso é muito gratificante. (José Maria)

0 depoimento de José Maria revela uma visão positiva da prática, a realização de um trabalho que "o faz alguém na vida", assim como o seu aluno. Essa compreensão orgulhosa do papel desempenhado pelo professor resignifica a prática docente e a escola rural.

0 tema da vocação se reveste de complexidade na medida em que pode estar ligado à idéia de acomodação, conformismo, servindo para escamotear as precárias condições de trabalho. É importante reafirmar que não há nessa discussão a intenção de apelar para uma "mística do desvelo" por parte do professor, como forma de encobrir as dificuldades vividas no desempenho da profissão, beneficiando os administradores da educação pública (Barreto, 1975, p. 108). Com o professor das escolas de assentamento essa discussão ganha uma qualidade diferente, pois a vocação é pensada numa perspectiva mais ampla, ligada a um projeto político no qual ele está presente como professor e como camponês.

Enquanto se constroem como homens e mulheres, como professores e professoras, encontram um papel importante para essa escola que se apresenta desgastada no meio rural, incluindo-a num projeto político importante 
para o campo.

Estudos sobre essa escola (Brandão, 1990; Martins, 1974) indicam que, considerando a maneira como se organiza, ela é a negação do mundo rural. O MST, porém, aposta numa escola que contribua para a afirmação desse mundo, na medida em que promove a cultura camponesa, trazendo para as práticas escolares seus saberes e riquezas. Assim, ao vislumbrar um novo papel para esses homens e mulheres professores, o Movimento também redefine a função da escola, numa visão diferenciada daquela que propunha a fixação do homem ao campo. Sua concepção valoriza elementos da cultura camponesa nos programas de ensino, dando novo sentido à escola rural, integrando-a num projeto amplo de educação da população camponesa.

Nesse projeto se resgata a identidade do professor e seu fazer orgulhoso, evidenciando a importância de seu trabalho como prática social. Os professores das escolas de assentamento vêem sua profissão re-significada, despertando o que muitos chamam de "dom".

Se a pessoa tem aquele dom para transmitir o conhecimento, para buscar. Se ela for uma pessoa responsável e gostar desse serviço, será sempre bem-vindo. Agora, se não gosta muito vai querer olhar pela questão do dinheiro. Então ele que procure outra profissão [risos]. 0 que a pessoa faz tem que ser pelo amor ao trabalho. (José Maria)

Não é, portanto, o salário a única gratificação esperada por esses professores e eles não se organizam em torno da categoria profissional docente, como aparece nos estudos de Peralva (1992) e Vianna (1999). 0 que os mobiliza é o desenvolvimento de práticas pedagógicas alimentadas na participação política no Movimento. Além de professores, também são homens e mulheres sem-terra e essa condição mobiliza e possibilita a afirmação da identidade coletiva.

A atuação dos professores das escolas de assentamento - na escola, na família, no Movimento - vai revelando como se tornam sujeitos de sua experiência educativa. Com o Movimento vão redefinindo seu papel na transformação da sociedade, possibilitando que tenham uma visão positiva do seu fazer pedagógico e social. 0 universo simbólico do MST ajuda a construir suas representações de homens e mulheres transformando a sociedade. É nesse sentido a afirmação de Melucci de que a identidade coletiva se refere a uma rede de relações ativas entre atores que interagem, influenciam-se mutuamente, negociam e tomam decisões (1996, p. 4). No seu processo de constituição, esses professores estão criando um sentimento de pertencimento que gera a afirmação da identidade coletiva. Produzem um sentimento positivo em relação à atividade profissional e política, um sentimento de orgulho. Uma consciência orgulhosa. A consciência não é imposta pelo MST, mas ele possibilita a reflexão, legitima o saber profissional e valoriza sua atuação. Resgata a vocação que o professor já possuía e contribui para alimentar-lhe a autoestima quando valoriza seu estilo de vida e a sua relação com a terra. As falas dos professores evidenciam o nível de compromisso com as discussões do Movimento:

A discussão da realidade da terra com os alunos é muito importante. Esses alunos são todos sem-terra também. Porque quem tem terra é o pai. Essa terra não dá para todos os filhos, só para a metade, a outra metade seria sem-terra. (José Maria)

Portanto a consciência orgulhosa não é sentimento externo, imposto, que vem de fora, é a pedra que ativa o que estava latente ou desaparecendo no professor. 0 Movimento é o instrumento que lhe permite olhar para si mesmo e perceber as condições para realizar um trabalho qualificado.

Esse sentimento leva a uma forte consciência da importância do trabalho do docente, favorecendo a construção da sua identida- 
de coletiva que, ao mesmo tempo em que alimenta essa consciência orgulhosa, é alimentada por ela. Cria-se um ir e vir do individual para o coletivo.

No entanto, no grupo de professores os diferentes níveis de adesão geram experiências diferenciadas, que se refletem nas práticas desenvolvidas na escola e no Movimento, que reforçam ou enfraquecem a consciência orgulhosa. Apesar de eles viverem experiências comuns, o modo de elaborá-las é diferente.

Para melhor compreender esse processo, agrupo os professores em situações distintas, analisando os fatores que interferem nessas diferenças. Essas posições não são fixas, os professores podem estar constantemente se movendo, ou seja, há momentos de participação mais intensa seguidos de maior distanciamento nas relações com o Movimento. Os motivos que levam a essa oscilação vão sendo revelados ao longo do estudo das práticas dos professores agrupados a partir de algumas características comuns.

Analisando esses pequenos grupos, percebo processos diferentes: uns expressam acentuadamente a consciência orgulhosa; em outros esse sentimento se manifesta de forma atenuada.

A partir dos depoimentos e da observação do dia-a-dia dos docentes, foi possível perceber os distintos níveis de envolvimento dos professores com o MST e com o trabalho pedagógico. Essas diferenças aparecem nos discursos sobre a participação no Movimento, na forma como explicitam sua trajetória, como se vêem no grupo de docentes, no valor que dão à profissão, no lugar que o Movimento ocupa em suas vidas e nos cuidados com que se preparam para o desempenho da prática docente.

Observando o universo dos entrevistados, também foi possível apreender as diversas maneiras como manifestam os níveis de adesão aos valores do MST, aos ideais e estratégias de luta e as relações entre os sujeitos que compõem o grupo de professores.

Partindo dessas indicações e de uma caracterização que foi se delineando de acordo com a maneira como expressam suas visões de mundo, sua representação como docentes e integrantes de um movimento social, procedi a uma distinção entre os professores. Num grupo estão os que desenvolvem vínculos fortes com Movimento e têm uma prática pedagógica valorizada. Participam de todas as atividades do MST, são as "lideranças". Demonstram adesão aos princípios e valores do grupo e defendem suas estratégias de luta. Na escola têm uma prática pedagógica alimentada nessa atividade política.

Num outro grupo, apresento os professores que demonstram vínculos atenuados. São os docentes que já tiveram forte participação e recordam com emoção esse passado, mas hoje sua ação é menos intensa. Demonstram adesão aos ideais do MST, porém sua prioridade é a prática na sala de aula. Participam dos encontros de professores na localidade e eventualmente vão aos grandes encontros.

Relaciono ainda os professores que apresentam vínculos fracos. Estão distanciados das atividades propostas pelo Movimento e não expressam com clareza o sentido da sua participação política. Isso também transparece num discurso desarticulado e sem entusiasmo quando falam da prática pedagógica.

Essas posições aparecem num processo dinâmico, nada é fixo. 0 quadro composto a partir do momento da coleta dos dados pode hoje apresentar outra composição. A construção desses sujeitos está em constante mudança, pois o que caracteriza a identidade é o perecimento da sua definição, que está sempre em processo (Montero, 1987, p. 15). Podem aparecer situações novas no seu cotidiano desencadeadas na escola, fora dela ou nas relações do mundo rural - que redimensionam sua atuação.

Dessa maneira, a identidade não é um dado adquirido, não é uma propriedade, não é um produto, é um lugar de lutas e de conflitos, é um espaço de construção de maneiras de ser e de estar na profissão (Nóvoa, 1995, p. 15). 
Por isso, o autor considera mais adequado falar em "processo identitário", realçando a mescla dinâmica que caracteriza a maneira como cada um se sente e se diz professor.

As reflexões de Nóvoa contribuem para evidenciar como os docentes "se sentem e se dizem professores". Os relatos apontam para a satisfação que sentem por pertencer ao Movimento e participar da proposta de educação, mesmo com as dificuldades mencionadas.

Analisei as diferentes possibilidades de construção da consciência orgulhosa ou até a sua ausência. Essas análises vão revelando situações e diferentes envolvimentos dos professores com a prática docente e a participação no Movimento.

Observando o conjunto dos professores entrevistados, é possível concluir que os mais integrados ao Movimento são os que desenvolvem trabalho diferenciado, original. Eles têm oportunidade de reelaborar constantemente seu pertencimento ao participar dos momentos da mística do grupo, que reforçam o conjunto das significações profundas, as visões grandiosas e as paixões fortes que mobilizam e inspiram as pessoas e os movimentos no caminho das mudanças e da superação de dificuldades. É fundamental viver esses momentos que mate-rializam a unidade invisível do grupo e possibilitam ao professor ativar seus recursos e sentir-se orgulhoso da sua condição de camponês, professor e cidadão.

Os vínculos fortes não levam a uma militância tradicional, pois existe um elemento que demanda de forma diferente o seu fazer político, que é o trabalho docente. É ali que se traduz em práticas esse envolvimento. Nesse sentido, os encontros possibilitam que o fazer político se entrelace com o pedagógico. Os professores são militantes da educação, seus investimentos políticos se concretizam na educação. Destacam-se por ser professores e lideranças na escola, sua militância está muito ligada ao fazer e ser professor, não é descolada da profissão, o que qualifica a experiência educativa, possibilitando mudanças no contexto rural, pela educação diferenciada que oferece às crianças.

Nas conclusões do trabalho destaco as peculiaridades dessa prática que faz com que os professores desenvolvam um sentimento positivo em relação ao seu trabalho, uma consciência orgulhosa do percurso percorrido na construção da sua identidade docente.

Um primeiro olhar sobre a atividade pedagógica dos professores dos assentamentos investigados não os diferencia do cotidiano dos docentes das zonas rurais de outras regiões do país. Os baixos salários, a falta de oportunidades para formação e atualização profissional, a precariedade nas condições físicas das escolas, entre outros problemas, determinam difíceis condições de ensino e reproduzem um cenário já conhecido e com poucas perspectivas de mudança. No entanto, o contato com os professores de assentamentos foi revelando situações que determinam um novo olhar sobre suas práticas e mostram como eles redescobrem e constroem a identidade profissional centrada na auto-estima, conscientes do valor social do seu trabalho. São sentimentos que os impulsionam a buscar a constante atualização dos conhecimentos pedagógicos e a refletir sobre a atividade docente no campo, conscientes de que sua prática integra um amplo projeto de educação.

A análise dos dados colhidos me permite concluir que a participação dos professores no Movimento transforma sua atividade docente, ampliando seu aprendizado e as relações de solidariedade presentes na cultura do mundo rural. Nas áreas de assentamento, criam-se compromissos entre os trabalhadores que descobrem o poder social da sua organização, que por sua vez respalda sua construção como cidadãos. Nesse processo, vai emergindo nos professores uma nova consciência do seu trabalho, a consciência 
orgulhosa do fazer docente.

0 processo de construção dessa prática se realiza na escola, nos espaços educativos propiciados pelo Movimento, nos contatos com o grupo de docentes, nos estudos que desenvolvem, nas trocas com os alunos, enriquecidas pela cultura camponesa. 0 professor se torna mais seguro para fazer escolhas e acrescentar elementos significativos aos conteúdos escolares organizados pelos sistemas de ensino. E, com isso, ele reelabora o espaço da escola no meio rural.

Evidencia-se aí a possibilidade de veiculação, na escola, de uma dimensão do saber enriquecida pela ação política, gerada nas práticas coletivas. Essa experiência possibilita aos professores a descoberta do significado do seu poder na relação com o sistema de ensino e na sociedade como um todo.

As situações vividas na escola são absorvidas e reorganizadas pelos docentes, levando ao crescimento profissional. São fundamentais para a formação do professor e para a construção e o fortalecimento do seu "jeito de ensinar".

0 trabalho que vem sendo feito pelo MST junto com professores abre possibilidades para a construção de identidades num processo de res- gate da dignidade dessas populações historicamente excluídas. Isso faz emergir a consciência orgulhosa do fazer docente, que leva o professor a construir um jeito de ensinar segundo a sua cultura e a simbologia da vida camponesa.

Porém, essa experiência do MST com os professores está em processo, precisa ser alimentada constantemente nos encontros com o grupo de docentes e nas diversas situações de aprendizagem. A experiência dos professores não se desenvolve de maneira homogênea: alguns se envolvem de maneira intensa, outros necessitam de maior acompanhamento, mas inegavelmente 0 Movimento é uma referência importante no quadro de precariedades da escola no meio rural. Essa relação amplia as possibilidades de construção de um saber docente enriquecido nos vários momentos de pertencimento.

Partindo dessa perspectiva, é possível pensar o trabalho dos professores das escolas de assentamento numa direção que lhes permita reelaborar os conhecimentos organizados pelos programas oficiais e oferecer uma formação de qualidade, possibilitando construir-se a si próprios e aos alunos como sujeitos do processo educativo.

\section{Referências bibliográficas}

ALENCAR, J. F. A professora "leiga": um rosto de várias faces. In: Eoucação e escola no campo. São Paulo: Papirus, 1993.

ANDRÉ, M.D. de. Etnografia da prática escolar. São Paulo: Papirus, 1995.

ARROY0, Miguel. Escola, cidadania e participação no campo. Em Aberto, Brasília, v. 1, n. 8, 1982.

BARRETO, Elba S. de S. Professores de periferia: soluções simples para problemas complexos. Cadernos de Pesquisa, São Paulo, n. 14, 1975

BRANDÃo, C. R. Casa de escola. São Paulo: Papirus, 1983.

O trabalho de saber. cultura camponesa e escola rural. São Paulo: FDT, 1990.

CALDART, R. S. Escola é mais do que escola na pedagogia do movimento sem terra. Porto Alegre; 1999. Tese (Doutorado em Educação) — Programa de Pós-graduação em Educação, Universidade Federal do Rio Grande do Sul, 1999.

CALVO, B. Etnografia de la educación. Nueva Antropologia, México, 1992.

CARVALHO, M. P. No coração da escola. São Paulo: Xamã, 1999. 
CAVACO, Maria Helena. Ofício de professor: o tempo e as mudanças. In: NÓVOA, A. (Org.). Profissão professor. Porto: Porto Editora, 1995.

DAVIS, Claudia; GATTI, Bernadete. A dinâmica da sala de aula na escola rural. In: THERRIEN, J.; DAMACENO, M. (Org.). Educação e escola no campo. São Paulo: Papirus, 1993.

FONSECA, Maria T. L. A extensão rural no Brasil: um projeto educativo para o capital. São Paulo: Loyola, 1989.

GOODSON, I. F. Dar voz ao professor: as histórias de vida dos professores e seu desenvolvimento profissional. In: NÓVOA, A. (Org.). Vidas de professores. Porto: Porto Editora, 1992.

KRAMER, Sonia; SOUZA, Solange. Histórias de professores: leitura, escrita e pesquisa em educação. São Paulo: Ática, 1994.

MARTINS, José de S. A Valorização da escola e do trabalho no meio rural. Revista Debate e Crítica, São Paulo, n. 2, p. 112-132, jan./jun. 1974.

MELUCCI, Alberto. Nomads of the present. social moviments and individual needs in contemporary societys. Filadelfia: Temple; Un. Press, 1989.

. A experiência individual na sociedade planetária. Lua Nova, São Paulo, n. 38, 1996.

1997.

Movimentos sociais e sociedade complexa. Movimentos Sociais na Contemporaneidade, São Paulo, n. 2, p.11-32, abr.

MERCADO, R. Prefácio de aula: espaço de conhecimento, lugar de cultura. Campinas: Papirus, 1994.

MOITA, Maria Conceição. Percursos de formação e de trans-formação. Porto: Porto Editora, 1995.

MONTERO, Paula. Considerações a respeito da noção de identidade. Comunicações do ISER, Rio de Janeiro, v. 6, n. 26, jul. 1987.

NÓVOA, António (Org.). Profissão professor. Porto: Porto Editora, 1995.

Vidas de professores. Porto: Porto Editora, 1995.

OSORES, Norma F. F. Identidades masculinas: varones de classe media en el Peru. Lima: PUC - Peru, 1997.

PERALVA, Angelina T. Reinventando a escola: a luta dos professores públicos do estado de São Paulo na transição democrática.

1992. Tese (Livre Docência em Educação). Faculdade de Educação, Universidade de São Paulo, São Paulo, 1992.

PERRENOUD, Philippe. Práticas pedagógicas, profissão docente, formação. Perspectivas sociológicas. Lisboa: Publicações Dom Quixote, 1997.

ROCKWELL, E. La escuela económica. México: Centro de Investigación y de Estudios Avanzados - IPN, 1987.

SACRISTÁN, Gimeno J. Consciência e acção sobre a prática como libertação profissional dos professores. In: NÓVOA, A. (Org.). Profissão professor. Porto: Porto Editora, 1995.

TARDIF, M.; LESSARD, C.; LAHYE, L. Os professores face ao saber. esboço de uma problemática do saber docente. Teoria e Educação, Porto Alegre, n. 4, 1991.

THERRIEN J. (Org.). A professora rural: o saber de sua prática social na esfera da construção social da escola no campo. In: EDUcAÇÃo e escola no campo. São Paulo: Papirus, 1993.

VIANNA, Claudia. Os nós do "nós": crise e perspectivas da ação coletiva docente em São Paulo. São Paulo: Xamã, 1999. 
Recebido em 22.03.02

Aprovado em 07.08 .02

Sonia Aparecida Branco Beltrame é doutora em Educação pela Faculdade de Educação da USP, professora de Licenciatura em Pedagogia e Pós-graduação em Educação do Centro de Ciências da Educação da Universidade Federal de Santa Catarina-UFSC. 